\title{
Risk of Infant Mortality Among Twins in Relation to Placental Abruption: Contributions of Preterm Birth and Restricted Fetal Growth
}

\author{
Cande V. Ananth,' John C. Smulian, ${ }^{2}$ Neela Srinivas,' Darios Getahun,' and Hamisu M. Salihu ${ }^{3}$ \\ ' Division of Epidemiology and Biostatistics, Department of Obstetrics, Gynecology, and Reproductive Sciences, University of Medicine and \\ Dentistry of New Jersey, Robert Wood Johnson Medical School, New Jersey, United States of America \\ 2 Division of Maternal-Fetal Medicine, Department of Obstetrics, Gynecology, and Reproductive Sciences, \\ University of Medicine and Dentistry of New Jersey, Robert Wood Johnson Medical School, New Jersey, United States of America \\ ${ }^{3}$ Department of Maternal and Child Health, School of Public Health, University of Alabama at Birmingham, \\ Alabama, United States of America
}

W hile preterm birth and restricted fetal growth are strongly associated with infant mortality, the extent to which these associations are modified by placental abruption remains unknown. A retrospective cohort study was carried out to examine the risk of infant mortality among twins in relation to abruption, and explore the independent contributions of preterm birth and restricted fetal growth to these associations. The study was restricted to women who had delivered twins at 22 weeks' gestation or more and fetuses weighing 500 grams or more in the United States (1989-2000). Risks of preterm birth (less than 37 weeks' gestation), fetal growth restriction and infant mortality, in relation to placental abruption, were evaluated. All analyses were adjusted for potential sociodemographic confounding factors. The association between restricted twin fetal growth and abruption was the strongest among the most severely growth-restricted babies (i.e., less than 1 centile), with the strength of association diminishing with increasing birthweight centiles. The risk of preterm birth among pregnancies with and without abruption were $80.1 \%$ and $51.9 \%$, respectively (relative risk [RR] 1.5, 95\% confidence interval [Cl] 1.4-1.6). The risk of small-for-gestational-age (SGA; birthweight of less than the 10th centile for gestational age) among abruption and nonabruption births was $11.7 \%$ and $9.2 \%$, respectively $(\mathrm{RR} 1.3,95 \% \mathrm{Cl} 1.2-1.4)$. Compared with twins of the appropriate growth delivered at term, the relative risks for infant mortality in the presence of abruption were $9.9(95 \% \mathrm{Cl}$ 5.4-18.2) for term-SGA, $25.0(95 \% \mathrm{Cl} 22.3-28.1)$ for preterm-non-SGA, and $36.2(95 \% \mathrm{Cl} 28.4-46.1)$ for preterm-SGA births. The association between infant mortality and abruption among twins appears largely mediated through preterm birth, and to a lesser extent, through SGA. The association between fetal growth and abruption is strongest among the severely growth-restricted babies, suggesting that the origins of placental abruption may develop in early pregnancy.

The recent two decades have witnessed a dramatic temporal increase in the incidence of twin births in the United States (US) and other industrialized countries (Ananth et al., in press; Ananth, Joseph, \& Kinzler, 2004; Ananth, Joseph, \& Smulian, 2004; Joseph et al., 2001; Kogan et al., 2000; Smulian et al., 2004). Between 1980 and 1999, the rate of twin births in the US increased by $53 \%$ (19.3 per 1000 births in 1980 to 28.9 per 1000 births in 1999; Kogan et al., 2000; Russell et al., 2003). While twins constitute approximately $3 \%$ of all births in the US, they account for up to $20 \%$ of all perinatal and infant deaths, as well as significant morbidity (Russell et al., 2003). In comparison to singletons, the risks of preterm birth (less than 37 weeks' gestation), stillbirth and perinatal mortality among twins are two- to fourfold higher (Salihu et al., 2003).

Placental abruption, a potentially devastating obstetric complication, is reported to complicate 5 to 15 per 1000 twin births (Ananth et al., 2001, 2003). Recently, Ananth and Wilcox (2001) showed that, among singleton births in the US, preterm, and smallfor-gestational-age (SGA) births accounted for $55 \%$ and $9 \%$ of excess perinatal deaths respectively, among women with placental abruption. Although the consequences of placental abruption on adverse perinatal

Received 19 April, 2005; accepted 14 June, 2005.

Address for correspondence: Dr. Cande V. Ananth, Division of Epidemiology and Biostatistics, Department of Obstetrics, Gynecology, and Reproductive Sciences, UMDNJ-Robert Wood Johnson Medical School, 125 Paterson Street, New Brunswick NJ 08901-1977, USA. E-mail: cande.ananth@umdnj.edu 
outcomes among singleton births are fairly welldescribed, similar population-based data among twins is lacking. Restricted fetal growth in twins can develop through mechanisms that differ from singletons, such as the unequal distribution of placental masses shared between the two fetuses, transplacental vascular anastomosis in monochorionic twin pregnancies, relative placental insufficiency, congenital anomalies, congenital infection, or a combination of these mechanisms (Ho \& Wu, 1978). This is in addition to mechanisms that overlap with singleton fetuses affected by restricted fetal growth. Similarly, etiologies for preterm birth may differ considerably between twins and singletons.

Given the particular spectrum of potential etiologies that contribute to preterm and SGA births among twins that differ from singletons (Zeitlin et al., 2001), this study was undertaken to evaluate the independent and separable contributions of preterm birth and restricted fetal growth on twin infant mortality in pregnancies complicated by placental abruption. It was also hypothesized that the magnitude of the preterm birth-mediated infant deaths associated with placental abruption among twins may be influenced by the preterm birth clinical subtypes, namely, preterm birth following ruptured membranes, medically indicated preterm birth and spontaneous preterm birth.

\section{Material and Methods US Twin Live Birth Cohort Composition}

Data from the US twin live birth data files 1989 through 2000, and the infant death data files from 1989 through 1991 and 1995 through 2000 were used to examine associations between placental abruption and adverse perinatal outcomes. These data correspond to birth and infant death certificates of live-born infants, assembled by the National Center for Health Statistics (NCHS) of the Centers for Disease Control and Prevention (National Center for Health Statistics, 1989-2000). Infant death data files for 1992 through 1994 were not linked to the corresponding live births by the NCHS. Therefore, analysis pertaining to infant mortality for the 1992 through 1994 periods was not performed.

Gestational age data, reported in completed weeks, were predominantly based on the date of the last menstrual period (LMP), and calculated as the difference between the date of the LMP and the date of delivery. In a small fraction (less than $5 \%$ ) of births that did not contain a valid date for the LMP, or when the menstrual-based gestational age was incompatible with birthweight, a clinical estimate of gestation, also contained on vital records, was used instead (Taffel et al., 1989). If a valid LMP month and year was available but the date was missing, gestational age (also in completed weeks) was imputed by the NCHS prior to release of the data (Taffel et al., 1982). The replacement of menstrual-based gestational age by a clinical estimate, as well as imputation of missing gestational age, was performed consistently for all years (1989 through 2000).

Placental abruption was defined as the complete or partial detachment of the placenta from the site of implantation in the uterine wall. The condition may produce severe abdominal pain and vaginal bleeding. In milder forms, an abruption may be diagnosed based on evidence of retroplacental bleeding or clots on the margin of the placental disc. A clinical diagnosis of abruption is usually documented by the physician or the attendant at the time of delivery.

\section{Perinatal Outcomes}

Preterm birth was categorized based on three clinical subtypes (Savitz et al., 1991): (1) preterm birth following ruptured membranes; (2) medically indicated preterm birth, defined as a preterm birth which followed iatrogenic intervention (labor induction or a primary or repeat cesarean delivery); and (3) spontaneous preterm birth, defined as preterm birth that was neither associated with ruptured membranes nor was medically indicated. Four check-box items on the live birth, fetal and infant death certificates were used to assign preterm birth clinical subtypes (Taffel et al., 1989). The item ruptured membranes accompanied by delivery at less than 37 weeks' gestation was used to identify women who delivered preterm following ruptured membranes. The items primary cesarean, repeat cesarean or labor induction accompanied by delivery at less than 37 weeks' gestation were combined to identify women who delivered preterm due to medical indications. The item corresponding to labor induction represents an attempt to induce labor, regardless of its success.

Fetal growth was assessed based on centiles of sexspecific birthweight-for-gestational-age, and categorized as less than $1 \%, 1 \%$ to $2 \%, 3 \%$ to $4 \%, 5 \%$ to $9 \%$, $10 \%$ to $90 \%$ and more than $90 \%$. SGA and large-forgestational-age were defined as infants with sex-specific birthweight less than the 10th centile and more than the 90th centile for gestational age respectively. Finally, infant mortality was defined as infant deaths within the first year of life.

\section{Statistical Analysis}

The risks of preterm and SGA birth were examined among women with and without placental abruption using the 'fetuses-at-risk' approach (Yudkin et al., 1987). The fetuses-at-risk approach allows estimation of risk based on the number of ongoing pregnancies (Joseph, 2004). In order to examine whether the risk of preterm birth was confounded by the mode of delivery, the analysis was stratified by twins delivered by cesarean and those delivered vaginally. Unadjusted relative risk (RR) and $95 \%$ confidence interval $(\mathrm{CI})$ were calculated as measures of effect.

In order to minimize possible effects due to confounding, adjusted relative risk was directly estimated from fitting multivariable logistic regression models. This was done by estimating the logistic regression 
model through a log-link (instead of the logit-link). All analyses were adjusted for maternal age (less than 20 years, 20 to 24 years, 25 to 29 years, 30 to 34 years, 35 to 39 years and 40 years or more), live-born parity (primiparous, parity 2 and parity 3 or more), maternal education (number of years of schooling: less than 12 years, and 12 years or more), lack of prenatal care or initiation of prenatal care beyond the first trimester, unmarried status, maternal race (White, Black or other race) and chronic hypertension. As these data files do not contain information on zygosity, all analyses were adjusted for infant sex as a partial proxy for zygosity. In a subanalysis, associations for smoking and alcohol use during pregnancy were further adjusted for owing to the large proportion of birth records with missing data on these exposures.

The population attributable fraction (PAF) was calculated using the relation $P_{d}[(R R-1) / R R]$, where $P_{d}$ refers to the proportion of cases in the population arising from the exposure group, and RR the adjusted relative risk (Rockhill et al., 1998). The PAF is interpreted as the proportion of the adverse outcome that could be attributed to the exposure (e.g., placental abruption). In other words, it refers to the proportion of the adverse outcome that could have been prevented had placental abruption not occurred. The attractiveness of this statistic is its public health impact.

Finally, the association between placental abruption and infant mortality among twins was examined. For this analysis, the joint effects of placental abruption, preterm birth and SGA births on the risk of infant death were examined.

\section{Data Exclusions}

Of all twin live births in the US between 1989 through 2000, the following categories were excluded: birthweight less than $250 \mathrm{~g}(n=2749)$, missing gestational age $(n=12,339)$, gestational age of less than 22 weeks $(n=10,876)$, gestational age of 44 weeks or more $(n=3374)$ and implausible birthweight/gestational age combinations $(n=5394)$. Another 125,303 twin pregnancies with missing data on placental abruption were also excluded. After all exclusions, 1,073,743 twin births remained for analysis.

The study was approved by the ethics review committee of the Institutional Review Board of UMDNJ-Robert Wood Johnson Medical School, New Jersey.

\section{$\overline{\text { Results }}$}

Table 1 shows the distribution of maternal characteristics in relation to placental abruption. Women with abruption were more likely to be less than 20 years or 35 years or more of age, multiparous with a previous preterm birth, unmarried, smokers, and with chronic hypertension, in comparison with those without abruption. Compared with women without placental abruption, those with abruption were more likely to be delivered by cesarean $(54.3 \%$ vs. $74.5 \%)$.

The gestational age-specific mean birthweight among twin live-borns was fairly similar in the abruption and nonabruption groups, although infants delivered at 30 weeks or more and born to women with abruption weighed approximately $100 \mathrm{~g}$ lower than those born to women without an abruption

Table 1

Maternal Characteristics in Relation to Placental Abruption: US Twin Live Births 1989 Through 2000

\begin{tabular}{|c|c|c|c|}
\hline \multirow[b]{2}{*}{ Maternal characteristics } & \multicolumn{2}{|c|}{ Placental abruption } & \multirow[b]{2}{*}{$p$ value } \\
\hline & $\begin{array}{c}\text { Absent (\%) } \\
N=1,060,216\end{array}$ & $\begin{array}{c}\text { Present (\%) } \\
N=13,527\end{array}$ & \\
\hline Maternal age in years & & & .016 \\
\hline$<20$ & 7.1 & 7.2 & \\
\hline $20-24$ & 20.0 & 19.9 & \\
\hline $25-29$ & 28.4 & 27.5 & \\
\hline $30-34$ & 28.0 & 28.0 & \\
\hline $35-39$ & 13.8 & 14.8 & \\
\hline$\geq 40$ & 2.6 & 2.7 & \\
\hline Live-born parity & & & $<.001$ \\
\hline Primiparous & 20.3 & 18.3 & \\
\hline Parity $\geq 2$, no prior preterm birth & 77.8 & 77.4 & \\
\hline Parity $\geq 2$, with $\geq 1$ prior preterm birth & 1.9 & 4.3 & \\
\hline Black maternal race & 18.3 & 21.2 & $<.001$ \\
\hline Unmarried marital status & 28.0 & 29.5 & $<.001$ \\
\hline Smoking during pregnancy & 13.9 & 19.1 & $<.001$ \\
\hline Chronic hypertension & 0.9 & 1.4 & $<.001$ \\
\hline Female infant sex & 49.8 & 48.5 & .003 \\
\hline Cesarean delivery & 54.3 & 74.5 & $<.001$ \\
\hline
\end{tabular}


Table 2

Risks of Small- and Large-for-Gestational-Age Birth in Relation to Placental Abruption: US Twin Live Births 1989 Through 2000

\begin{tabular}{lccccc}
\hline & \multicolumn{2}{c}{ Risk of SGA/LGA among } & & \multicolumn{2}{c}{ Adjusted associations for SGA/LGA birth } \\
\cline { 2 - 3 } \cline { 5 - 6 } Fetal growth centiles & $\begin{array}{c}\text { Nonabruption } \\
N(\%)\end{array}$ & $\begin{array}{c}\text { Abruption } \\
N(\%)\end{array}$ & & $\begin{array}{c}\text { Relative risk } \\
(95 \% \text { confidence interval) }\end{array}$ & $\begin{array}{c}\text { Attributable fraction } \\
(\%)\end{array}$ \\
\hline$<1 \%$ & $9062(0.9)$ & $242(1.9)$ & & $2.6(2.0,3.4)$ & 1.0 \\
$1 \%-2 \%$ & $19,038(1.9)$ & $349(2.7)$ & & $1.9(1.5,2.3)$ & 0.8 \\
$3 \%-4 \%$ & $19,686(1.9)$ & $299(2.3)$ & & $1.6(1.3,2.0)$ & 0.4 \\
$5 \%-9 \%$ & $47,631(4.6)$ & $689(5.3)$ & & $1.5(1.3,1.8)$ & 0.5 \\
$<10 \%$ (SGA) & $97,781(9.2)$ & $1579(11.7)$ & & $1.3(1.2,1.4)$ & 2.8 \\
$10 \%-90 \%$ & $826,149(80.5)$ & $11,514(80.3)$ & & $1.0($ Reference) & - \\
$>90 \%$ (LGA) & $105,295(10.3)$ & $998(7.6)$ & & $0.7(0.6,0.8)$ & - \\
\hline
\end{tabular}

Note: $\mathrm{SGA}=$ small-for-gestational-age; LGA = large-for-gestational-age.

Relative risks were adjusted for the confounding effects of birth year, maternal age, live-born parity, maternal education, unmarried marital status, black maternal race,

female infant sex and chronic hypertension.

(Figure 1, left panel). The risk of an SGA birth was dramatically higher among births to women with abruption compared with those born to nonabruption mothers, with the risk progressively widening with advancing gestational age (Figure 1, right panel). To further explore this relationship, fetal growth was examined within categories of birthweight centiles. The association between growth restriction and abruption was the strongest among the most severely growthrestricted babies (i.e., less than 1 centile), with the risk progressively declining with increasing birthweight centiles (Table 2).

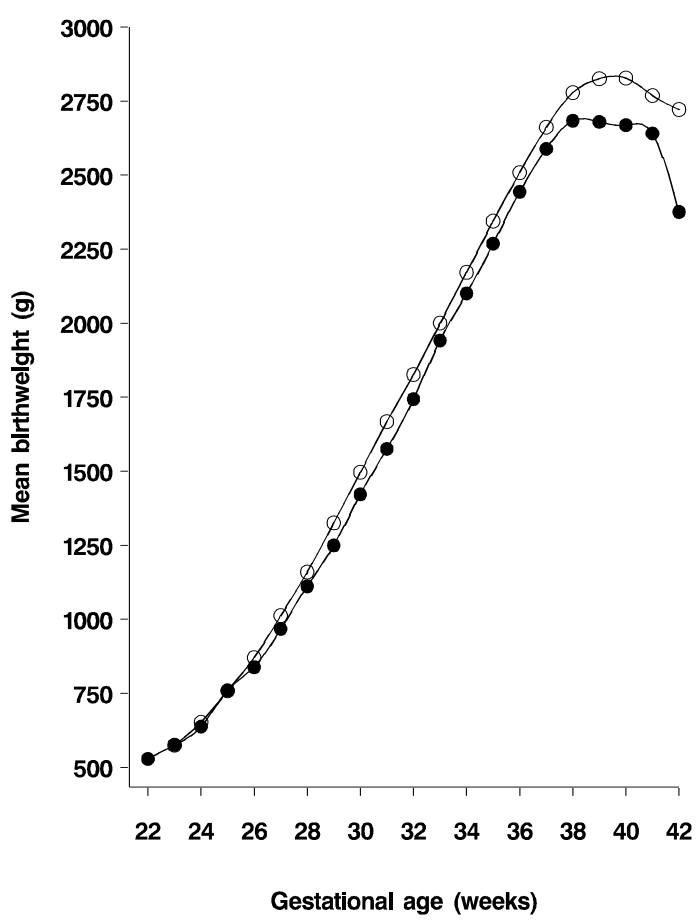

Table 3 shows the association between abruption and preterm birth among twin live births. The risk of a preterm delivery was higher among abruption compared with nonabruption births. When preterm births were examined within three clinical subtypes, its association with abruption was strongest with preterm births following ruptured membranes, and least among spontaneous preterm births. These patterns were stronger when preterm births were analyzed at less than 32 weeks' gestation. Although the association between abruption and preterm birth was greatest among preterm birth following ruptured membranes, the

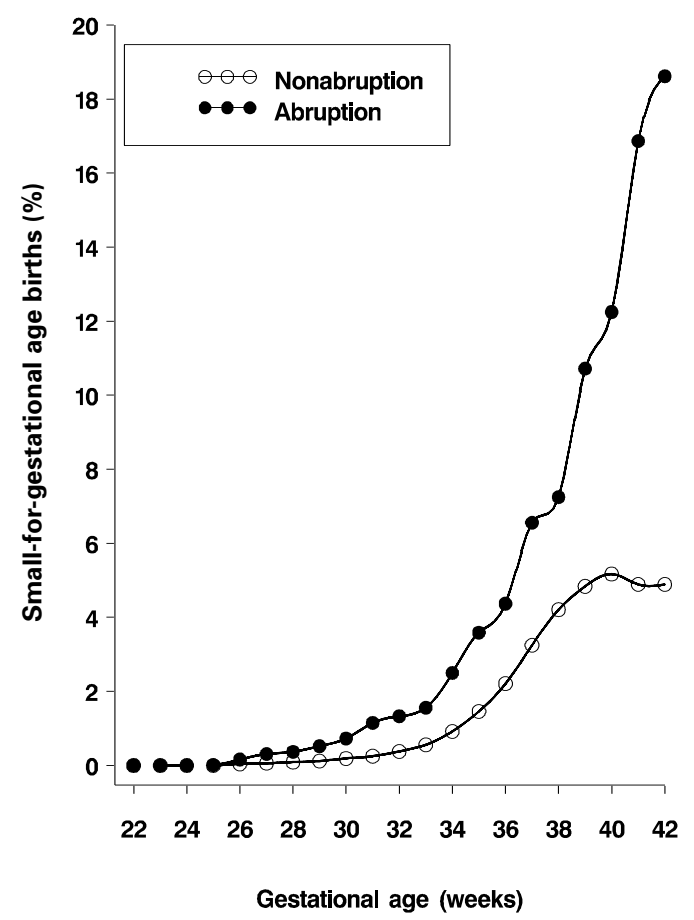

\section{Figure 1}

Gestational age-specific mean birthweight (left panel) and risk of small-for-gestational-age birth (right panel) among women with and without placental abruption: US twin live births, 1989 through 2000. 
Table 3

Risk of Preterm Birth in Relation to Placental Abruption: US Twin Live Births 1989 Through 2000

\begin{tabular}{|c|c|c|c|c|}
\hline \multirow[b]{2}{*}{ Preterm birth $<37$ weeks } & \multicolumn{2}{|c|}{ Risk of preterm birth among } & \multicolumn{2}{|c|}{ Adjusted associations for preterm birth } \\
\hline & $\begin{array}{c}\text { Nonabruption } \\
N(\%)\end{array}$ & $\begin{array}{l}\text { Abruption } \\
\quad N(\%)\end{array}$ & $\begin{array}{c}\text { Relative risk } \\
\text { (95\% confidence interval) }\end{array}$ & $\begin{array}{c}\text { Attributable fraction } \\
(\%)\end{array}$ \\
\hline Term birth ( $\geq 37$ weeks) & $497,509(48.1)$ & $2697(19.9)$ & 1.0 (Reference) & - \\
\hline Preterm birth (<37 weeks) & $537,097(51.9)$ & $10,830(80.1)$ & $1.5(1.4,1.6)$ & 26.7 \\
\hline Preterm PROM & $57,463(5.6)$ & $1513(11.3)$ & $4.0(3.7,4.4)$ & 8.5 \\
\hline Medically indicated & $263,795(25.6)$ & $6873(51.1)$ & $2.4(2.3,2.5)$ & 29.8 \\
\hline Spontaneous preterm birth & $213,079(20.7)$ & $2369(17.6)$ & $1.7(1.6,1.8)$ & 7.2 \\
\hline
\end{tabular}

Note: $\mathrm{Cl}=$ confidence interval; $\mathrm{PROM}=$ premature rupture of membranes.

Relative risks were adjusted for the confounding effects of birth year, maternal age, live-born parity, maternal education, unmarried marital status, black maternal race, female infant sex and chronic hypertension.

largest population attributable fraction $(29.8 \%)$ was for medically indicated preterm births.

The gestational age-specific rate of infant death among abruption and nonabruption births stratified by SGA status is shown in Figure 2. Live-born twin babies that were appropriately grown were at higher risk of dying during infancy in the abruption compared with the nonabruption group at virtually every gestational age (left panel). Among SGA babies, the risk of infant death was higher in the abruption than in the nonabruption groups (right panel). However, the risk of mortality in the abruption group among both was higher among those that were SGA than those that were appropriately grown. In other words, the association between abruption and infant deaths was modified by the SGA status.

Since abruption was strongly associated with increased risks of both preterm birth and fetal growth restriction, we examined how the association between abruption and infant mortality was modified by both of these factors (Table 4). Compared with twins of appropriate growth and delivered at term, the presence of either SGA or preterm birth in the absence of abruption conferred increased risk of infant deaths. In the presence of abruption, term-SGA births were associated with a 9.9-fold increased risk of infant mortality, whereas preterm-AGA births were associated with a 25 -fold increased risk of infant mortality. However,
Appropriate-for-gestational-age

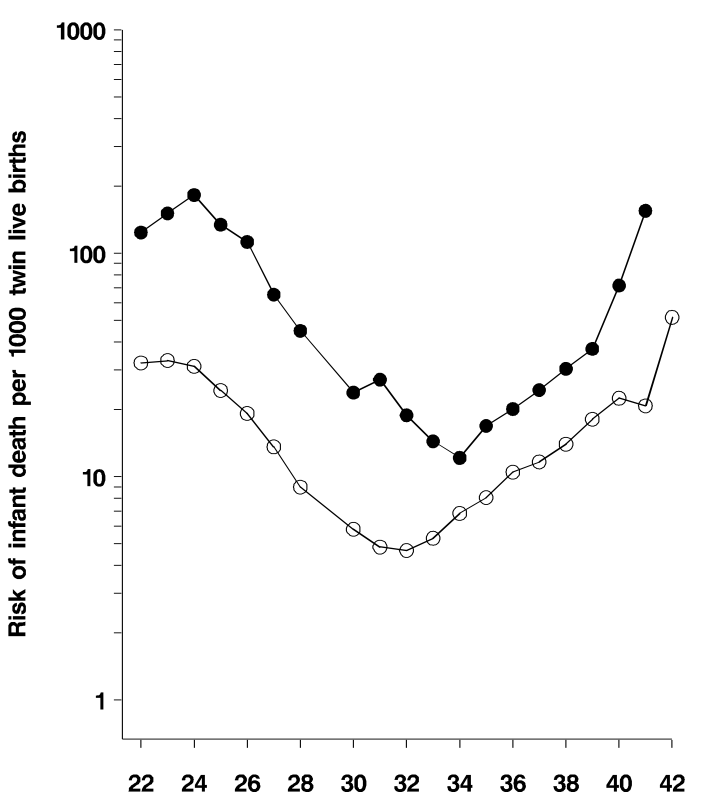

\section{Small-for-gestational-age}

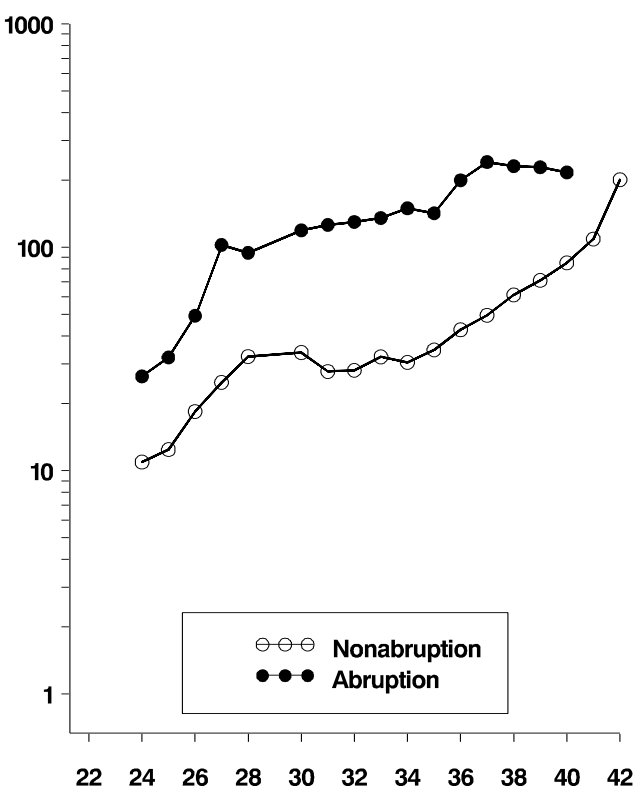

Gestational age (weeks)

Gestational age (weeks)

Figure 2

Gestational age-specific risk of infant mortality (per 1000 twin live births) in women with and without placental abruption.

The left panel corresponds to twins of appropriate growth, and the right panel corresponds to small-for-gestational-age births: US twin live births, 1989 through 2000. 
Table 4

Risk of Infant Mortality in Relation to Placental Abruption, Preterm Birth and Small-for-Gestational-Age Birth: US Twin Live Births, 1989 Through 1991 and 1995 Through 2000

\begin{tabular}{|c|c|c|c|c|}
\hline \multirow[b]{2}{*}{ Placental abruption } & \multirow[b]{2}{*}{ Total number of twin live births } & \multicolumn{3}{|c|}{ Twin infant mortality } \\
\hline & & $N$ (Risk per 1000) & $\mathrm{RR}(95 \% \mathrm{Cl})$ & Attributable fraction (\%) \\
\hline \multicolumn{5}{|l|}{ Nonabruption births } \\
\hline Non-SGA, term birth & 37,275 & $1170(3.5)$ & 1.0 (Reference) & - \\
\hline SGA birth only & 35,381 & $520(14.7)$ & $3.8(3.4,4.2)$ & 1.1 \\
\hline Preterm ( $<37$ weeks) birth only & 370,655 & $10,624(28.7)$ & $8.5(7.9,9.1)$ & 2.5 \\
\hline Both SGA and preterm birth & 339,121 & $2127(57.1)$ & $16.5(15.2,17.8)$ & 5.4 \\
\hline \multicolumn{5}{|l|}{ Placental abruption births } \\
\hline Non-SGA, term birth & 843 & $11(6.7)$ & $2.0(1.0,3.9)$ & 0.3 \\
\hline SGA birth only & 374 & $13(34.8)$ & $9.9(5.4,14.5)$ & 3.1 \\
\hline Preterm ( $<37$ weeks) birth only & 7189 & $567(78.9)$ & $25.0(22.3,28.1)$ & 7.6 \\
\hline Both SGA and preterm birth & 1638 & $97(115.1)$ & $36.2(28.4,44.1)$ & 11.2 \\
\hline
\end{tabular}

Note: $\mathrm{SGA}=$ small-for-gestational-age; $\mathrm{RR}=$ relative risk; $\mathrm{Cl}$ = confidence interval.

Relative risks were adjusted for the confounding effects of birth year, maternal age, live-born parity, maternal education, unmarried marital status, black maternal race, female infant sex and chronic hypertension.

preterm-SGA births with abruption conferred over 36fold increased risk of infant mortality. Over $11 \%$ of all twin infant deaths were attributable to SGA infants that were delivered preterm in the presence of abruption.

\section{$\overline{\text { Discussion }}$}

Several interesting and clinically important findings emerge from this population-based study of over a million live-born twins in the US. Most notably, the study confirmed our hypothesis that the association between placental abruption and infant mortality among twins is largely mediated through preterm delivery, and to a lesser extent, through reduced fetal growth. In addition, there appears to be a strong interaction among preterm birth, fetal growth restriction, and placental abruption on infant mortality in twin births, with growth-restricted, preterm twins born to women with abruption at the highest risk of dying during infancy. Although placental abruption is associated with increased risk of overall twin preterm birth, substantial variation in the magnitude of risks were evident based on preterm birth subtypes.

The association between abruption and restricted fetal growth has been consistent across several studies. However, the nature of the relationship is poorly understood. It is unclear whether abruption is a contributing etiology to growth restriction (Ananth et al., 1999; Ananth \& Wilcox 2001; Salihu et al., 2005), or is a consequence (Kramer et al., 1997; Krohn et al., 1987; Rasmussen et al., 1999; Voigt et al., 1990). A recent study of singleton gestations speculated that, given that the association between abruption and fetal growth restriction was strongest among the severely growthrestricted babies (i.e., less than 1 centile), with progressively declining risk with advancing birthweight centiles, the origins of abruption must lie in midpregnancy or perhaps even earlier (Ananth \& Wilcox, 2001).
This suggests that abruption and fetal growth restriction may be distinct clinical manifestations of similar underlying pathophysiologies, or that abruption may be the end result of a long-standing chronic process. Our present study in twins corroborates these general findings (Table 3). Although we support the general thesis that chronic or early abruption can precede restricted fetal growth, we are unable to examine the relationship in terms of causality in light of the retrospective nature of our data. Prospective cohort studies coupled with intermittent Doppler velocimetry assessments of the umbilical arteries may shed more light on the causality of the purported associations.

An observation in our study that merits discussion pertains to the analysis of placental abruption and twin preterm birth (Table 3). Although preterm birth was strongly associated with placental abruption, strong heterogeneity was found in the association based on preterm birth subtypes. The association between preterm birth and abruption was strongest with preterm birth following ruptured membranes, followed by medically indicated preterm birth, and lastly with spontaneous preterm birth. These findings are new, and offer important insights into management of patients with the possibility of developing an abruption. The association between preterm birth following ruptured membranes and abruption is expected as in the presence of ruptured membranes, ascending infections including chorioamnionitis are likely to be precipitating factors (Ananth, Oyelese, et al., 2004; Major et al., 1995; Vintzileos et al., 1987). Medically indicated preterm birth, on the other hand, is typically necessitated in the presence of serious fetal or maternal compromise, and follows induction of labor or cesarean delivery for pregnancy complications (Ananth, Joseph, \& Kinzler, 2004; Ananth, Joseph, \& Smulian, 2004; Joseph et al., 2002). A vast majority of twin 
pregnancies (over 55\%) in the US are delivered by cesarean (Kontopoulos et al., 2004) due to maternal or fetal complications, including placental abruption. While the association between abruption and medically indicated preterm birth is modest, the large etiologic fraction $(42.2 \%)$ is significant from a public health perspective.

The associations among SGA, preterm birth, and placental abruption indicate the presence of overlapping etiologies, and increase the risk of recurrences of these conditions in subsequent pregnancies (Rasmussen et al., 2000, 2001). In women with an abruption, underlying placental insufficiency and maternal malnutrition compound the risk of twin SGA births. It is therefore plausible that women with histories of preterm or SGA births may be at an increased risk of placental abruption in a subsequent pregnancy (Rasmussen et al., 1999).

\section{Limitations and Strengths}

The limitations of the study are typical of populationbased studies, including likely errors in gestational age estimation based on last menstrual period, unexplored risk factors, residual confounding and confounding by indication in the diagnosis of abruption. The vital statistics data does not contain information on maternal anthropometry such as maternal prepregnancy body mass index, drug or substance use during pregnancy, and genital tract and amniotic infections. These variables have been shown to be risk factors for preterm and SGA births, as well as for placental abruption. Another limitation was the inability to adjust for the clustering of outcomes within twin sibships as the two fetuses from a twin pregnancy were not identified in the data. While failure to account for this clustering may lead to imprecise variance estimates of effect measures, it is unlikely to negate the powerful associations among placental abruption, preterm delivery, restricted fetal growth and infant mortality.

The different subtypes of preterm births share common determinants, and hence an increase in a particular subtype may result in a decrease in another subtype. For instance, an increased awareness of the signs and symptoms of labor can lead to an increase in spontaneous preterm birth at the expense of preterm birth following ruptured membranes. Similarly, women with spontaneous preterm labor who subsequently delivered by cesarean may have been classified as medically indicated preterm birth. The possibility of confounding by indication in the diagnosis of placental abruption is likely in the study. As the risk of abruption is greater at preterm than at term, physicians caring for preterm (twin) pregnancies are more likely to carefully look for an abruption, compared with a (twin) pregnancy approaching term. Another limitation of the data was the inability to assess patterns of associations between placental chorionicity, placental abruption and infant mortality. Finally, examination of the association between placental abruption and infant mortality between 1992 and 1994 was not possible, as these data were unavailable. It is unlikely that the temporal pattern of associations between abruption and mortality is different between these periods in comparison to the available data. The population-based nature of the study on placental abruption among twin births is perhaps the largest reported to date, and offers generalizability of findings.

\section{Conclusions}

In summary, our study underscores the independent contributions of preterm birth and restricted fetal growth on abruption-associated infant mortality among twin births. The large etiologic fractions for twin preterm birth in relation to placental abruption suggest that efforts to identify women at risk of developing placental abruption may be beneficial in reducing untoward pregnancy outcomes. Exploration of genetic determinants of placental abruption may provide one avenue for targeted interventions.

\section{Acknowledgments}

Drs Ananth, Smulian, Srinivas and Getahun are partially supported through a grant (R01-HD038902) from the National Institutes of Health awarded to Dr Ananth.

The authors thank Dr Anthony Vintzileos for critically reviewing the manuscript, and for offering several comments that improved it. The authors also thank Susan Fosbre for assistance in the preparation of the manuscript.

\section{References}

Ananth, C. V., Berkowitz, G. S., Savitz, D. A., \& Lapinski, R. H. (1999). Placental abruption and adverse perinatal outcomes. The Journal of the American Medical Association, 282, 1646-1651.

Ananth, C. V., Demissie, K., \& Hanley, M. L. (2003). Birth weight discordancy and adverse perinatal outcomes among twin gestations in the United States: The effect of placental abruption. American Journal of Obstetrics and Gynecology, 188, 954-960.

Ananth, C. V., Joseph, K. S., Demissie, K., \& Vintzileos, A. M. (in press). Trends in preterm birth subtypes among twins in the United States, 1989 through 2000: Impact on perinatal mortality. American Journal of Obstetrics and Gynecology, 193.

Ananth, C. V., Joseph, K. S., \& Kinzler, W. L. (2004). The influence of obstetric intervention on trends in twin stillbirths in the United States. The Journal of Maternal-Fetal \& Neonatal Medicine, 15, 380-387.

Ananth, C. V., Joseph, K. S., \& Smulian, J. C. (2004). Trends in twin neonatal mortality in the United States: Influence of obstetric intervention. American Journal of Obstetrics and Gynecology, 190, 1313-1321.

Ananth, C. V., Oyelese, Y., Srinivas, N., Yeo, L., \& Vintzileos, A. M. (2004). Preterm premature rupture of membranes, intrauterine infection, and oligohydramnios: Risk factors for placental abruption. Obstetrics and Gynecology, 104, 71-77. 
Ananth, C. V., Smulian, J. C., Demissie, K., Vintzileos, A. M., \& Knuppel, R. A. (2001). Placental abruption among singleton and twin births in the United States: Risk factor profiles. American Journal of Epidemiology, 153, 771-778.

Ananth, C. V., \& Wilcox, A. J. (2001). Placental abruption and perinatal mortality in the United States. American Journal of Epidemiology, 153, 332-337.

Ho, S. K., \& Wu, P. Y. K. (1978). Perinatal factors and neonatal morbidity in twin pregnancy. American Journal of Obstetrics and Gynecology, 122, 979-987.

Joseph, K. S. (2004). Incidence-based measures of birth, growth restriction, and death can free perinatal epidemiology from erroneous concepts of risk. Journal of Clinical Epidemiology, 57, 889-897.

Joseph, K. S., Allen, A. C., Dodds, L., Vincer, M. J., \& Armson, B. A. (2001). Causes and consequences of recent increases in preterm birth among twins. Obstetrics and Gynecology, 98, 57-64.

Joseph, K. S., Demissie, K., \& Kramer, M. S. (2002). Obstetric intervention, stillbirth, and preterm birth. Seminars in Perinatology, 26, 250-259.

Kogan, M. D., Alexander, G. R., Kotelchuck, M., MacDorman, M. F., Buekens, P., Martin, J. A., \& Papiernik, E. (2000). Trends in twin birth outcomes and prenatal care utilization in the United States, 1981-1997. The Journal of the American Medical Association, 283, 335-341.

Kontopoulos, E. V., Ananth, C. V., Smulian, J. C., \& Vintzileos, A. M. (2004). The impact of route of delivery and presentation on twin neonatal and infant mortality: A population-based study in the USA, 1995-97. The Journal of Maternal-Fetal \& Neonatal Medicine, 15, 219-224.

Kramer, M. S., Usher, R. H., Pollack, R., Boyd, M., \& Usher, S. (1997). Etiologic determinants of abruptio placentae. Obstetrics and Gynecology, 89, 221-226.

Krohn, M., Voigt, L., McKnight, B., Daling, J. R., Starzyk, P., \& Benedetti, T. J. (1987). Correlates of placental abruption. British Journal of Obstetrics and Gynaecology, 94, 333-340.

Major, C. A., de Veciana, M., Lewis, D. F., \& Morgan, M. A. (1995). Preterm premature rupture of membranes and abruptio placentae: Is there an association between these pregnancy complications? American Journal of Obstetrics and Gynecology, 172, 672-676.

National Center for Health Statistics. (n.d.). 1989-2000 linked birth/infant death data set. (Department of Health and Human Services, Centers for Disease Control and Prevention NCHS CD-ROM series 20, No. 3-21). Hyattsville, MD: National Center for Health Statistics.

Rasmussen, S., Irgens, L. M., Albrechtsen, S., \& Dalaker, K. (2001). Women with a history of placental abruption: When in a subsequent pregnancy should special surveillance for a recurrent placental abruption be initiated? Acta Obstetricia et Gynecologica Scandinavica, 80, 708-712.
Rasmussen, S., Irgens, L. M., \& Dalaker, K. (1999). A history of placental dysfunction and risk of placental abruption. Paediatric and Perinatal Epidemiology, 13, 9-21.

Rasmussen, S., Irgens, L. M., \& Dalaker, K. (2000). Outcome of pregnancies subsequent to placental abruption: A risk assessment. Acta Obstetricia et Gynecologica Scandinavica, 79, 496-501.

Rockhill, B., Newman, B., \& Weinberg, C. (1998). Use and misuse of population attributable fractions. American Journal of Public Health, 88, 15-19.

Russell, R. B., Petrini, J. R., Damus, K., Mattison, D. R., \& Schwarz, R. H. (2003). The changing epidemiology of multiple births in the United States. Obstetrics and Gynecology, 101, 129-135.

Salihu, H. M., Aliyu, M. H., Rouse, D. J., Kirby, R. S., \& Alexander, G. R. (2003). Potentially preventable excess mortality among higher-order multiples. Obstetrics and Gynecology, 102, 679-684.

Salihu, H. M., Bekan, B., Aliyu, M. H., Rouse, D. J., Kirby, R. S., \& Alexander, G. R. (2005). Perinatal mortality associated with abruptio placenta in singletons and multiples. American Journal of Obstetrics and Gynecology, 193, 198-203.

Savitz, D. A., Blackmore, C. A., \& Thorp, J. M. (1991). Epidemiologic characteristics of preterm delivery: Etiologic heterogeneity. American Journal of Obstetrics and Gynecology, 164, 467-471.

Smulian, J. C., Ananth, C. V., Kinzler, W. L., Kontopoulos, E., \& Vintzileos, A. M. (2004). Twin deliveries in the United States over three decades: An age-period-cohort analysis. Obstetrics and Gynecology, 104, 278-285.

Taffel, S., Johnson, D., \& Heuse, R. (1982). A method of imputing length of gestation on birth certificates. Vital and Health Statistics, (Series 2, No. 93), 1-11.

Taffel, S. M., Ventura, S. J., \& Gay, G. A. (1989). Revised US certificate of birth: New opportunities for research on birth outcome. Birth, 16, 188-193.

Vintzileos, A. M., Campbell, W. A., Nochimson, D. J., \& Weinbaum, P. J. (1987). Preterm premature rupture of the membranes: A risk factor for the development of abruptio placentae. American Journal of Obstetrics and Gynecology, 156, 1235-1238.

Voigt, L. F., Hollenbach, K. A., Krohn, M. A., Daling, J. R., \& Hickok, D. E. (1990). The relationship of abruptio placentae with maternal smoking and small for gestational age infants. Obstetrics and Gynecology, 75, 771-774.

Yudkin, P. L., Wood, L., \& Redman, C. W. G. (1987). Risk of unexplained stillbirth at different gestational ages. Lancet, 1, 1192-1194.

Zeitlin, J. A., Ancel, P. Y., Saurel-Cubizolles, M. J., \& Papiernik, E. (2001). Are risk factors the same for small for gestational age versus other preterm births? American Journal of Obstetrics and Gynecology, 185, 208-215. 